\title{
DRUGS, TSARS AND ECONOMIC DEVELOPMENT
}

\author{
David W. Rasmussen*
}

It seems that America names a Tsar whenever we decide to focus on a policy problem, as though that title is associated with effective policies which are well administered. The appointment of a drug Tsar, the implicit policies that are associated with the War on Drugs, and the political environment that spawned these policy initiatives yield an interesting story about misguided public policy dominated by unintended secondary effects. Drug policy reveals much about the paralysis of public policy in contemporary America and, more specifically to our purpose here, suggests why it is so difficult to generate a serious local or regional development policy. It also suggests important directions for future research.

Politicians, with the aid of an apparently witless press, have created a national hysteria about drugs that is rooted in the same reality that produced the 1930 s film "Reefer Madness." War was declared. The War on Drugs has much in common with the one in Vietnam in that it is based on hot rhetoric and little commitment. They share a fundamental flaw - political support for each War exists only in the absence of a requirement to pay for it. How can an issue be our "number one problem" when we are unwilling to allocate additional resources to its resolution? Indeed, drugs are an unlikely candidate for the number one problem except in a world of diminished international tensions, relatively stable prices, and relatively low unemployment. The tragic consequences of drugs are overwhelmingly borne by minorities who are killed in fights over market share, die of overdoses, and are imprisoned for participation in this industry. My reading of the American electorate suggests this is not the description of a problem compelling the white middle class to action.

The generic political television ad in Florida shows a prison cell slam shut, with the voiceover telling us that the candidate is tough on crime (or drugs or traffickers). Once elected the candidates try to be tough. Florida has a determinant sentencing system in which the legislature sets up guidelines for judges, in order to assure that individuals who commit the same crime get approximately the same sentence when the criminal record is comparable.

Professor of Economics and Policy Sciences, Florida State University. This paper was presented as the presidential address at the 29th meeting of the Southern Regional Science Association, March 24, 1990 in Washington, D.C.
The legislature has increased sentences and made some crimes, including drug offenses, more serious. The antidrug climate has increased the ardor of many players in the system, resulting in ever increasing numbers of people incarcerated in our prisons. In December 19861,960 persons were admitted to Florida's prisons; the same month in 1989 saw 3,395 enter the prison system. Since prison capacity is limited due to a Federal court decree, the increased number of admissions is translated directly into earlier release. The average prisoner only serves one-third of his sentence, down from the traditional 50 percent. Some serve as little as 16 percent of their sentence. Prison sentences have lost so much of their sting that offenders now sometimes plea bargain for a prison sentence rather than probation, a punishment that is regarded as too intrusive for a longer period of time. This is getting tough on crime in Florida.

Police resources are obviously limited. The legal code can be viewed as a menu of crimes that police may enforce, but their limited resources require that they engage in selective enforcement. Police are willing soldiers in the War on Drugs. Police resources, as measured by arrests, have been diverted away from the index crimes (which include violent and property crimes) in favor in drug arrests. Drug arrests as a proportion of total index crime arrests rose 41 percent from 1983 to 1987, from .25 to .36 . Over 37 percent of all Florida prison admissions this year are for drug crimes.

Colleagues and I at Florida State have explored the unintended side effects associated with this reallocation of resources: they include a decline in the probability of arrest for index crimes which results in about 17 percent more reported property offenses per 100 career criminals. The war on drugs results in a lower probability of arrest for violent and property crime, more admissions to prison, reduced prison sentences, and probably an increased number of criminals if the severity and certainty of punishment have the deterrence effects reported in the economics of crime literature.

Politicians are tough on crime in order to solidify their position with voters. Their motivation is clear. Motivation for the police to reallocate resources to drug offenses is understandable for a budget maximizing bureaucrat. Not only may the police budget be increased if they are engaged in the War on Drugs, they also benefit by 
the fact they keep fines and forfeitures resulting from drug busts.

Drug policy is formulated in and shaped by a political environment that a Tsar, particularly Nicholas II, could appreciate since it is short sighted and doomed to failure. An examination of our stand on drugs reveals important generic policy problems that must be overcome if we are to generate a coherent regional development policy in this country.

Our War on Drugs and regional development policy have four common attributes: 1) inadequate human capital investment is a core issue; 2) the time horizon of policy makers is shorter than required for effective policy alternatives; 3) income redistribution necessarily accompanies each policy, a fact that is complicated by the racial distribution of the benefits of policy initiatives; and 4) the geography of the problem spans the entire nation while responsibilities for the programs and policies reside with state and local government.

Persons participating in the illicit drug industry have a characteristic shared by many geographic areas in need of economic development-they embody too little human capital to be competitive in our economy. Indeed, in some cases the populations are the same, for the central cities of our large metropolitan areas are targeted for local economic development and are centers of heavy drug activity as well. In other places, such as the rural south and that region's black belt, human capital investment is one of the usual litany of development policies.

It would seem that regional scientists with an interest in development would have a keen interest in the burgeoning literature on the efficacy of schooling. While I recognize the merits of a division of labor, we who recommend policies for development should take responsibility for knowing something about them. A recent book on development in the rural south, for example, recommended increasing schooling expenditures so to attract better teachers (Lyson, 1989). This recommendation comes despite the fact there is no evidence that increased expenditures, ceteris paribus, raises any measures of student achievement(Hanushek, 1984). Unfortunately, weapparently do not know much about the educational production function, especially for the individuals who are of direct concern to scholars and policy makers interested in policy issues related to economic development, drugs, poverty, productivity decline, and inequality. The efficacy of human capital investment is the essence of many policy issues, and this subject should perhaps be better integrated into our research agenda.

This brings us to myopia, the second problem of development policy that is suggested by drug policy. Drug crime, as well as some other offenses, can be characterized as having three foci for policy intervention. The first is to affect the propensity to commit the crime. A substantial economics of crime literature suggests this means raising the individual's opportunity cost of illegal activity. It does not require a Nobel Laureate in economics to understand that a surgeon has less incentive to commit serious crimes than a person who can only occasionally command the minimum wage. Policies to raise the opportunity cost of the at-risk population probably include improved access to prenatal care, expansion of early enrichment programs, and efforts to mold school curricula that results in lower drop out rates and greater achievement.

These programs may be cost effective in the long run, but in the short run they have no impact on drug use and related crime. More to the politician's liking is the short term pay-off which is provided by the other two anti-crime policies - greater efforts to arrest the current generation lost on drugs and to build more prisons to house them. The combined effects of budgetary restrictions and myopia is to reduce our investment in people and raise our expenditures on punitive measures. The myopia demonstrated in our conduct of the War on Drugs is generic to our public policy. Development policies are similarly limited, for it is the long term investment in people that is a prerequisite for the enrichment of many economically depressed places.

Racism, implied if not explicit, is the third element of our War on Drugs that has important implications for understanding development policy. Blacks are disproportionately represented among incarcerated drug offenders in Florida. Blacks account for 15 percent of Florida's population, 52 percent of inmates convicted for index crimes, and 73 percent of prisoners whose primary offense is drugs.

How does one account for this? The police allocate their resources among crimes by a process that is not well understood. Florida police departments, like those of other states, face too many demands given their resources, and achieve only 15 arrests for every 100 reported offenses against property. We are told that drugs account for most crime, so law enforcement resources are reallocated from a host of crimes, including white middle class pleasures of speeding and driving under the influence, to victimless drug crimes that are apparently commited by blacks. It is an ideal arrangement. The white middle class benefits because it can discourage drug use among their children by invoking the threat of legal sanctions for drug users. The police can blame the low probability of arrest for property crimes on the drug industry, thereby benefiting from an apparent need for more resources. Blacks, in contrast, are arrested and imprisoned.

Our myopic and ineffective drug policy is tolerated in part because its costs are borne disproportionately by 
blacks. Correspondingly, an effective long term policy that raises the life chances of blacks and lowers the probability of drug use would overwhelmingly benefit blacks rather than whites. An effective policy would almost surely raise the tax burden of the white majority. Similar distributional issues also constrain local and regional development policies, particularly when a large portion of the affected population is minority. Development efforts in the black belt counties of the South and many central cities of our large metropolitan areas may be compromised by this residual expression of the more virulent racism of our past.

Naming a Tsar for important policy problems is not entirely foolish. As a symbol of centralized authority, naming a Tsar reflects the reality that many communities and regions of the country share common problems and potential solutions. For example, programs and policies that facilitate human capital investment among the relevant populations are not unique to each community. Every community needs compensatory education measures, curriculum reform and, perhaps more important, diversity of curriculum. For local and regional economic development there is a more direct link with the national economy. A recent study (Rasmussen and Zuehlke, 1990) of economic growth among the states suggests that the national growth rate and the business cycle are the primary determinants of state economic growth. State policy variables such as tax rates, right to work status, and welfare expenditures play a relatively modest role in determining annual growth rates, as does the convergence hypothesis that is based on the relative economic status of a state. Perhaps the urge to appoint a Tsar comes from this knowledge that we all swim in the same ocean.

Unfortunately, the common problem set does not mean the solutions will be found at the national level. Local initiatives and perhaps increasing competition at the local level will generate the most innovation in many areas, including drug treatment, education and economic development initiatives.

There is an impressive unity of problems. National productivity growth is compromised, among other reasons, by deficient investment in human capital. Lower productivity growth reduces the growth of per capita income, which, on the margin, lowers our propensity to invest in people. Rising human capital requirements for decent jobs limit the economic opportunity of the ill educated. Completing the circle, poverty and the host of related problems are perpetuated and concentrated in the places we see as candidates for local and regional development.

Regional science has important analytical tools with which to analyze problems of economic development. Yet the problems and policies that constrain developmentlike those that plague drug policy - are not usually discussed by our discipline. This orientation is probably rooted in the methods origin of our discipline, which has been compounded by an apparent fascination among social scientists with science for its own sake. Not incidentally, academics respond to the prevailing fashion in the journals, which through the peer review process, are profoundly conservative in the pursuit of new methods and directions of research.

The issues of regional development policy highlighted by our brief excursion into drug policy-the myopia that seems inherent in our political process, the selfcenteredness of our culture which is particularly acute when matters of race are concerned, and our ineffectiveness in investing in human capital among the populations most in need - are nota regular part of our research agenda nor our discourse at meetings. Other disciplines address these issues with varying degrees of success, but none raise them in the context in which they are particularly relevant- local and regional development. The most concrete of these issues, the problem of human capital investment in a regional development context, is ours for the taking. It may be the paramount issue of our day. Let us add it to our already full research agenda.

\section{References}

Hanushek, Eric A., "The Economics of Schooling", Journal of Economic Literature, Vol. XXIV, No. 3, 1984, pp 11411177.

Ledebur, Larry and David W. Rasmussen, "Let's Try a Federalist Industry Policy", Challenge, November/December, 1983, pp 58-60.

Lyson, Thomas A., Two Sides of the South: The Growing Divergence Between the Rural and Urban South, New York: Praeger, 1989.

Rasmussen, David W. and Thomas W. Zuehlke, "Sclerosis, Convergence and Taxes: Determinants of Growth Among the American States", Environment and Planning C: Govemment and Policy, Vol. 8, No. 1, 1990, pp 1-11. 